\title{
FROM THE SPECIAL ISSUE EDITORS
}

\section{SUSTAINABLE DEVELOPMENT FOR A BETTER WORLD: CONTRIBUTIONS OF LEADERSHIP, MANAGEMENT, AND ORGANIZATIONS}

On September 25, 2015, all 193 member countries of the United Nations (UN) adopted a set of 17 Sustainable Development Goals (SDGs) designed to end poverty, protect the planet, and ensure prosperity for all as part of a new global "Agenda 2030" (United Nations, 2015). Building on the earlier UN Millennium Development Goals and seeking to complete what had been left undone, this new agenda for sustainable development laid out a bold ambition:

"We are resolved to free the human race from the tyranny of poverty ... and to heal and secure our planet. We are determined to take the bold and transformative steps which are urgently needed to shift the world on to a sustainable and resilient path. As we embark on this collective journey, we pledge that no one will be left behind." (United Nations, 2015: 1)

The 17 SDGs (see Table 1) and their 169 detailed targets cover a range of issues, from gender equality to inclusive and sustainable cities, from peace to biodiversity, from healthy lives to decent work, from climate change to poverty, with many other areas covered as well. Notably, the efforts to achieve these diverse and ambitious goals are to be undertaken in an "integrated and indivisible" manner, "balanc[ing] the three dimensions of sustainable development: the economic, social and environmental." (United Nations, 2015: 1). Also important, businesses were heavily involved in the development of the SDGs and are seen as critical partners in enabling their achievement, in contrast to the Millennium Development Goals. Agenda 2030 "call[s] upon all businesses to apply their creativity and innovation to solving sustainable development challenges" (United Nations, 2015: 29). Closely related initiatives have framed the SDGs explicitly in terms of business responsibilities and opportunities (e.g., SDG Compass: The Guide for Business Action on the SDGs, 2015.).

If the sheer volume of activity they have spurred is any indication, the SDGs have struck a chord. Many business organizations across a wide variety of sectors are now framing their environmental, social, and governance (ESG) actions in terms of the SDGs. According to surveys conducted in 2015 by PwC, 71 percent of businesses had started to take action in understanding how the SDGs impacted their operations and outcomes, and 90 percent of citizens indicated that it was important for businesses to sign up to the SDGs (PwC, 2015). In addition, academic research on the SDGs has taken off at a dramatic rate; Google Scholar searches on publications from 2015 onwards reveal more than 50,000 citations for the term "sustainable development goals" and more than 25,000 citations for this term in combination with "business." Analysis by the Web of Science group of more than 10,000 published articles on SDG topics reveals a comprehensive map of research clusters and their connections (see Figure 1; Nakamura, Pendlebury, Schnell, \& Szomszor, 2019). One key insight is that research on health and health care (right hand side of Figure 1) is nearly as great in volume as that on environment, agriculture, and other aspects of sustainability combined (left hand side of Figure 1). Linkages between these domains are made through only a handful of areas, notably water supply and sanitation. Otherwise, the Web of Science analysis indicates a largely scattered and isolated set of discrete research conversations on the SDGs.

How does $A M D$ 's special issue on "Sustainable Development for a Better World" fit into this dispersed dialogue? What can we as management scholars add to the conversation? And in what ways might our research contribute to helping businesses and other organizations achieve the audacious agenda?

\section{THE VALUE OF MANAGEMENT SCHOLARSHIP ON SDGs}

There are several ways in which we as management scholars are uniquely positioned to contribute to making progress on the SDGs. First, our research approaches and methodologies enable us to observe and make sense of interactions across multiple levels of analysis. This is crucial for understanding progress on and roadblocks to the SDGs, which implicate actions at the individual, group, organizational, sector, and institutional levels and manifest at local, regional, national, and global scales. Other disciplines tend to specialize at one or a few levels of analysis, potentially isolating or privileging action at those levels. By contrast, as a field built on diverse disciplinary traditions, 
TABLE 1

United Nations SDGs

Goal 1: End poverty in all its forms everywhere

Goal 2: End hunger, achieve food security and improved nutrition, and promote sustainable agriculture

Goal 3: Ensure healthy lives and promote well-being for all at all ages

Goal 4: Ensure inclusive and equitable quality education and promote lifelong learning opportunities for all

Goal 5: Achieve gender equality and empower all women and girls

Goal 6: Ensure availability and sustainable management of water and sanitation for all

Goal 7: Ensure access to affordable, reliable, sustainable, and modern energy for all

Goal 8: Promote sustained, inclusive, and sustainable economic growth; full and productive employment; and decent work for all

Goal 9: Build resilient infrastructure, promote inclusive and sustainable industrialization, and foster innovation

Goal 10: Reduce inequality within and among countries

Goal 11: Make cities and human settlements inclusive, safe, resilient, and sustainable

Goal 12: Ensure sustainable consumption and production patterns

Goal 13: Take urgent action to combat climate change and its impacts*

Goal 14: Conserve and sustainably use the oceans, seas, and marine resources for sustainable development

Goal 15: Protect, restore, and promote sustainable use of terrestrial ecosystems, sustainably manage forests, combat desertification, and halt and reverse land degradation and halt biodiversity loss

Goal 16: Promote peaceful and inclusive societies for sustainable development, provide access to justice for all, and build effective, accountable, and inclusive institutions at all levels

Goal 17: Strengthen the means of implementation and revitalize the global partnership for sustainable development
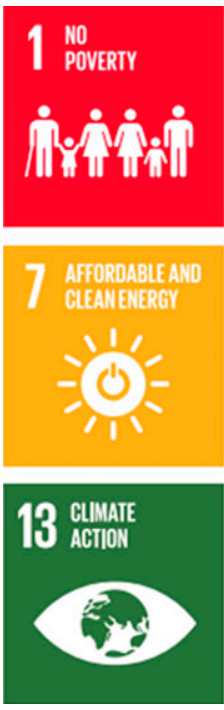
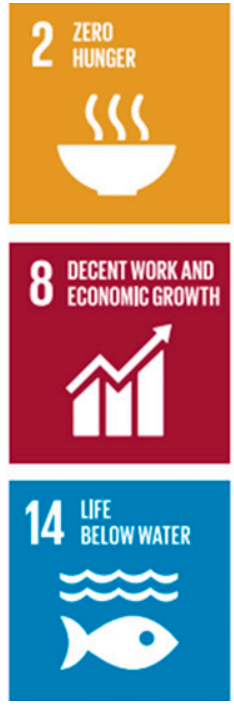
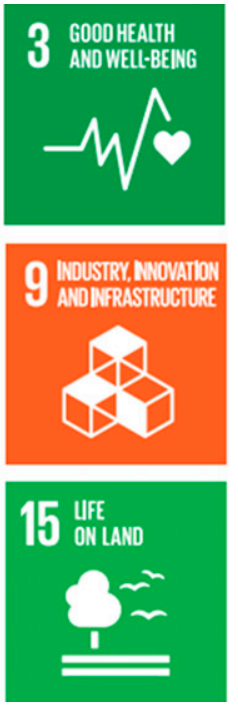
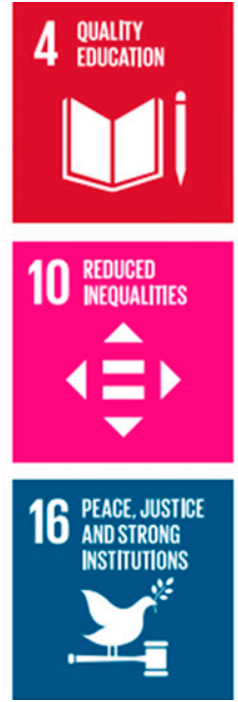
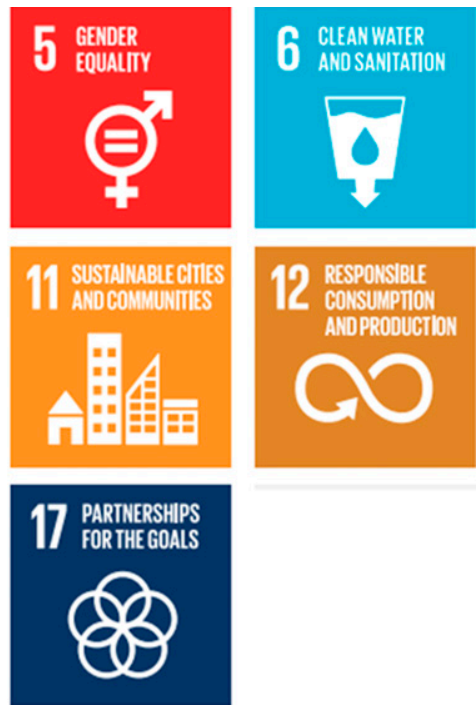

* Acknowledging that the United Nations Framework Convention on Climate Change is the primary international, intergovernmental forum for negotiating the global response to climate change.

Source: SDGs: 17 goals to transform our world, United Nations, at http://www.un.org/sustainabledevelopment/

management scholarship is well suited to examining how macro-level pressures, constraints, and institutions influence individual behavior, and vice versa.

Second, our multidisciplinary roots give us the conceptual and theoretical footings needed to grapple with the causal threads that contribute to pursuit of the SDGs. By definition, the SDGs represent "grand challenges," which are characterized by complex causality, interactions between and among diverse stakeholders, and multiple incommensurate evaluative criteria (Ferraro, Etzion, \& Gehman, 2015; George, HowardGrenville, Joshi, \& Tihanyi, 2016). Conceptual tools in the management field that accommodate how meanings, actions, and arrangements are constructed, perpetuated, and changed across complex settings are thus particularly valuable in gaining insight. We, however, must not fall prey to grasping too tightly our existing theoretical and conceptual tools. Sustainable development is not simply a new research topic or research context, but a new research paradigm, for it assumes a normative outcome (social equity, functioning life-support systems) and a systems perspective, which recognizes interconnections between natural and social systems (Bansal, 2019). This context demands interdisciplinary perspectives, transdisciplinary theoretical lenses, and, consistent with $A M D$ 's mission, the opening of new theoretical lines of sight.

Finally, management scholars typically orient toward real-world puzzles. This is critical because it is only through an explicit focus on practical problems, 
FIGURE 1

Web of Science Analysis of Research on Themes Related to the SDGs (Source: Nakamura et al., 2019)

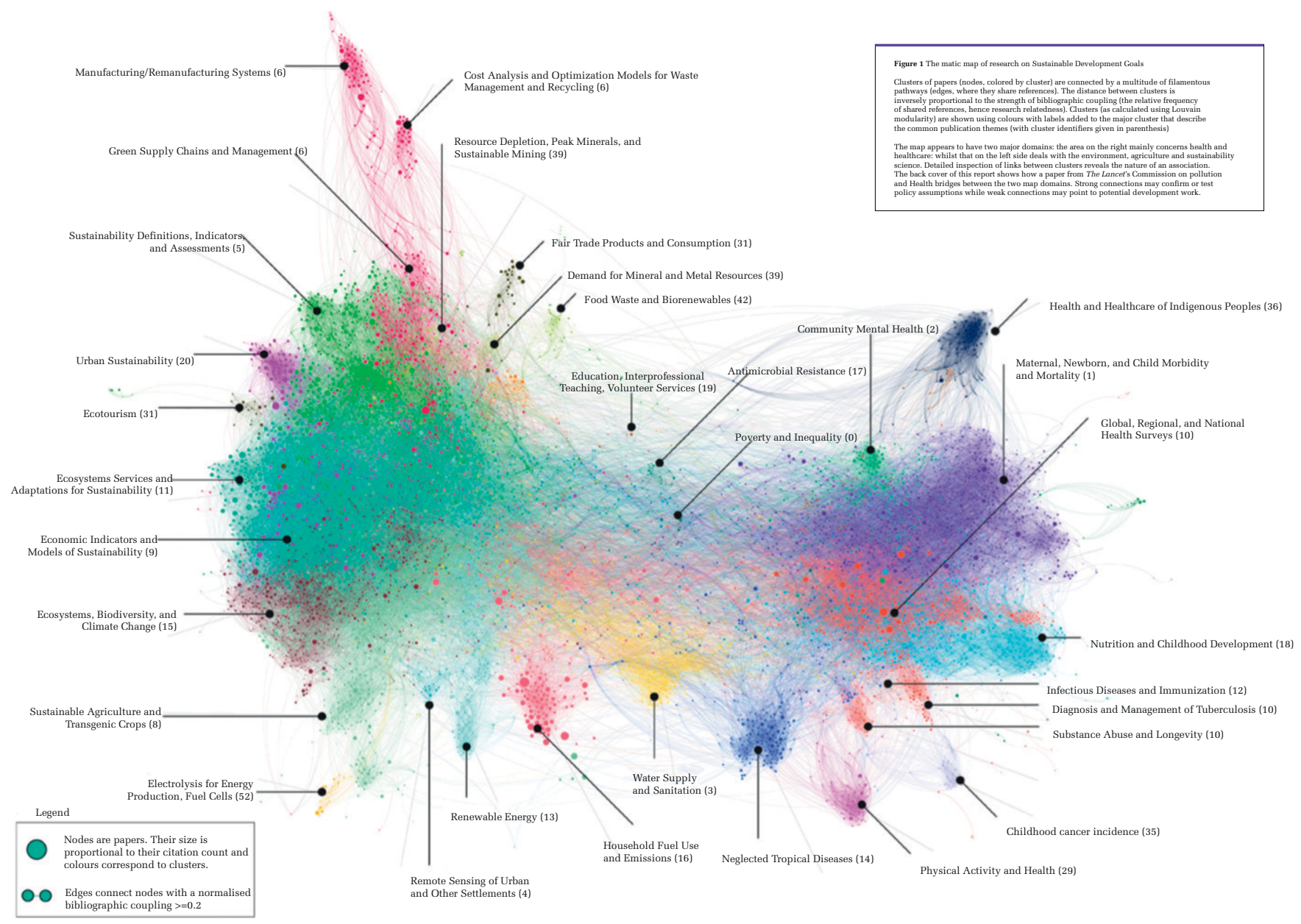

Copyright (@) Clarivate Analytics. Clarivate Analytics is a trademark of its respective owner and used herein with permission.

and accountability to those most affected by these problems, that science and social science contribute to solutions (Sarewitz, 2016). The SDGs define a series of very clear real-world problems and highlight the constituents most affected by them. Hence, they are solid guides for problem-oriented research.

Our field, however, can be rightly critiqued for having proliferated too many theories, prescriptions, and answers to nonplussing questions (as have other social sciences (Watts, 2017) and indeed basic and applied sciences (Sarewitz, 2016) been similarly critiqued). Such variety at best complicates but at worst can mislead the very constituents who might benefit from our work. One of the editors of this special issue, Jerry Davis, has compared management studies with the Winchester Mystery House, built in San Jose, California, by an heiress to the Winchester rifle fortune (2015). With no overall objective other than to keep building continuously over a 40-year period, the resulting house is an agglomeration of individually well-constructed but collectively incoherent elements: stairways that lead nowhere, doors that do not open, and stained-glass windows in rooms that admit no light. We seem to live in a similar house, where individual theories, methods, and articles may be executed to the highest standard, but where novelty for the sake of novelty is pursued in isolated projects, resulting in multiple and sometimes inconsistent answers to the same question. This tendency must be curbed if we are to build a useable base of knowledge that will help with the achievement of the SDGs.

Considering all of our gifts, treasures, and faults, management scholars have a golden opportunity to make a real difference in the world by orienting more of our research efforts toward the SDGs. This reorientation would be consistent with recent calls for responsible research within the management field, an emphasis on striving for both rigor and relevance by studying societally important questions (cRRBM, 2017). We should draw from our collective nimbleness across levels of analysis as well as our conceptual composure in embracing complexity, yet rein in our tendency to pick up familiar theoretical tools and to 
keep building just for the sake of building. To be sure, conducting useful problem-oriented social science holds real challenges, as Watts (2017: 3) notes:

Health, education, inequality, cultural norms, economic policies, and physical environments all interact in complicated ways to produce particular individual and group outcomes. Attempts to understand or influence these outcomes in the real world therefore often result in a difficult choice between focusing on such a small part of the problem that one misses the larger picture, and drowning in complexity.

Watts advocates for social scientists to choose "Goldilocks" problems—ones that are neither too big nor too small-to make genuine progress. In this volume, we believe authors have offered inspiring proof of concept that management scholars are eminently capable of selecting such problems for study and applying rigorous qualitative and quantitative methodologies that yield theoretical insights and practical implications. We invite scholars to build from these positive examples and explore how the SDGs define a set of problems that can lead them to act more like Goldilocks and less like Sarah Winchester.

In the remainder of this essay, we first put the SDGs and their aspirations into the context of existing business and management research, much of which has been problem- and solution-focused. We then provide an overview of the themes that arise out of the articles included in the special issue, which helps to illustrate some of the new ways in which our scholarship can inform business action on sustainable development. Finally, we conclude with a call for further research and engagement in key directions suggested by the research included in this special issue.

\section{BUILDING ON EXISTING MANAGEMENT RESEARCH IN SUSTAINABLE DEVELOPMENT}

Scholarship on corporate social responsibility and business impact on the natural environment goes at least as far back as the 1987 publication of the Bruntland Report, which broadly defined the term sustainable development and advocated for its principles (for useful overviews of past research on corporate social responsibility and the natural environment, see handbooks such as Bansal \& Hoffman, 2012; Crane, McWilliams, Matten, Moon, \& Siegel, 2008). Furthermore, management scholars have recognized that business practices are at the heart of many of the complex issues captured by the SDGs. Extant management research, however, has only begun to explore and inform practices related directly to achieving the SDGs.

In the work to date, our field has laid some important groundwork needed for tackling issues related to the SDGs. These efforts capture processes and phenomena within and across levels of analysis and leverage theoretical lenses familiar to management scholars. Using labels such as societal "grand challenges" (George et al., 2016) or "wicked problems" (Rittell \& Webber, 1973), management researchers have examined how complex institutional arrangements and organizational configurations both perpetuate and mitigate problems such as climate change (Schüssler, Rüling, \& Wittneben, 2014), inequality (Mair, Wolf, \& Seelos, 2016), and exploitative supply chain practices (Kim \& Davis, 2016). The lenses of social movement theory (Luo, Zhang, \& Marquis, 2016), framing (Ansari, Wijen, \& Gray, 2013), organizational design (Majchrzak, Griffith, Reetz, \& Alexy, 2018), and robust action (Ferraro et al., 2015) have been useful in exploring grand challenges. Focusing on how individuals can shift frames and actions, accounts also have explored how people frame desired changes for their peers (Bansal, 2003; Howard-Grenville, Nelson, Earle, Haack, \& Young, 2017) and document the challenges involved (Sonenshein, DeCelles, \& Dutton, 2014; Whiteman \& Cooper, 2011). Finally, at the individual level within organizations, management scholars have offered insights into issues raised by the SDGs by considering stress, coping, and well-being (Gaines \& Jermier, 1983; Xie \& Johns, 1995); income (Judge, Piccolo, Podsakoff, Shaw, \& Rich, 2010; Leana \& Meuris, 2015); justice (Colquitt, Conlon, Wesson, Porter, \& Ng, 2001); and status differences (Marr \& Thau, 2014; Pettit, Yong, \& Spataro, 2010).

Although the variety and scope of existing management scholarship related to the SDGs holds promise, it is at risk of being lost in, or having its impact tempered by, the multiple conversations in which it resides. Similar to the building of the Winchester Mystery House, we have been adding too much complexity and novelty rather than building something that clearly and coherently contributes to well-defined problems. There now are subfields on sustainable development in most, if not all, functional areas within the broader umbrella of management scholarship. These different topical streams are not effectively integrated with one another, and their integration into mainstream journals is a relatively recent development. In addition to overly narrow perspectives and lack of integration, academic discussion remains characterized by limited shared definitions of key concepts, lack of agreement on useful theoretical approaches, and measures that are very diverse and highly debated (Montiel \& Delgado-Ceballos, 2014).

Obstacles to progress are not limited just to scholarship on topics related to the SDGs. Business organizations, too, face obstacles as they tend to grapple with the goals through narrow consideration of the "business case" for their own organizations (Bansal, 
2019; Schaltegger \& Wagner, 2006). Although sustainability management is becoming more widespread among major companies, corporate efforts frequently do not richly reflect the overall state of the world (Dyllick \& Muff, 2016; Whiteman, Walker, \& Perego, 2013). PwC's 2015 survey found that businesses prioritized the specific SDGs that held most promise for business growth, essentially "cherry picking" a few relevant SDGs rather than anticipating how they could impact all 17. By far, businesses reported prioritizing SDG 8 (decent work and economic growth) because impact in this area could be regarded as most straightforward; conversely, other goals (such as SDG 14, life below water; or SDG 1, no poverty) have been seen as holding limited opportunity for businesses. This pattern of thought and action suggests there is considerable work to be done not only to understand more holistically the SDGs and their interrelationships with business activities but also to point businesses toward evidence-based insights, tools, or resources that might better guide actions and practice. Without these efforts from the academic community, there may be little hope of achieving the ambitious agenda laid out through the SDGs.

\section{KEY THEMES REPRESENTED IN THE SPECIAL ISSUE}

We now explore the themes represented by the eight articles in this special issue as we consider how they make progress in building our evidence base and insights into problems defined by the SDGs. Table 2 gives an overview of the articles and their SDG emphases, key findings, and implications. We discuss the articles here in terms of how they illustrate the three features outlined previously: their multilevel foci; their conceptualization of phenomena that opens up, rather than reduces, complexity; and their tackling of Goldilocks-size real-world problems. We close with a discussion of further opportunities for management scholarship on the SDGS to consider a broader range of the goals and geographies where their impact is most needed and to leverage our full toolkit of methodological approaches and levels of analysis.

\section{Theme 1: Multilevel Foci}

Many of the articles consider interactions across levels of analysis and their roles in making progress on the SDGs. Some articles draw attention to how the actions of individuals can give rise to broader scale shifts. For example, in exploring how a for-profit firm seeded sustainable and effective cross-sector partnerships (CSPs), Bode, Rogan, and Singh ("Sustainable Cross-Sector Collaboration: A Global Platform for Social Impact") show how individuals developed structures and processes within the firm that overcame the challenges to corporate involvement in CSPs. Drawing on in-depth interviews of 26 individuals and a survey of 665 employees (participants and nonparticipants in the social impact projects), these authors demonstrate how the alignment of various individuals' interests enabled development of CSPs. These included senior leaders' interests in improving employee retention, employees' interests in pursuing meaning through their work, and social purpose organization members' interests in accessing highly trained talent. SDG 17 explicitly calls for the creation of partnerships as a means to achieve the other goals, and this article demonstrates how such notably challenging CSPs can be built through concerted actions at the individual level. Hertel, Bacq, and Belz ("It Takes a Village to Sustain a Village: A Social Identity Perspective on Successful Community-Based Enterprise Creation") offer another example of how actions and interactions ripple up to create durable social outcomes. Through qualitative case studies of two community-based enterprises (CBEs) in rural Germany, these authors find that people's identification with their community together with the emergence of a new enterprising identity facilitate collective mobilization needed to spark and sustain CBE creation. At the community level, lasting commitment to CBEs can be further reinforced through rituals and artifacts.

At a broader level of analysis, but nonetheless showing the importance of cross-level interactions, the article by Rousseau, Berrone, and Gelabert ("Localizing Sustainable Development Goals: Nonprofit Density and City Sustainability") uses quantitative analysis of the density of local environmental nonprofit organizations (LENOs) within 100 U.S. metropolitan areas over a 12-year period to investigate the relationship between organizations (in this case, LENOs) and urban-scale outcomes. The authors find that cities with higher density of LENOs have greater reductions in toxic pollution over time and higher rates of adoption of voluntary environmental standards at the city level; notably, higher income inequality in a city suppresses the relationship between LENOs and city sustainability. This article and the one by Hertel, Bacq, and Belz have important implications for SDG 11 (sustainable cities and communities) as they shed light on how individual identity, organizational presence (or absence), and social demographics contribute to the attainment of community or urban level outcomes.

Finally, one article addresses the influence of the collective on the individual, demonstrating multilevel interactions from the other direction. Goodman and Kaplan draw on an ethnographic study of women's employment in rural India to show how employment decisions are strongly shaped by a woman's household. 


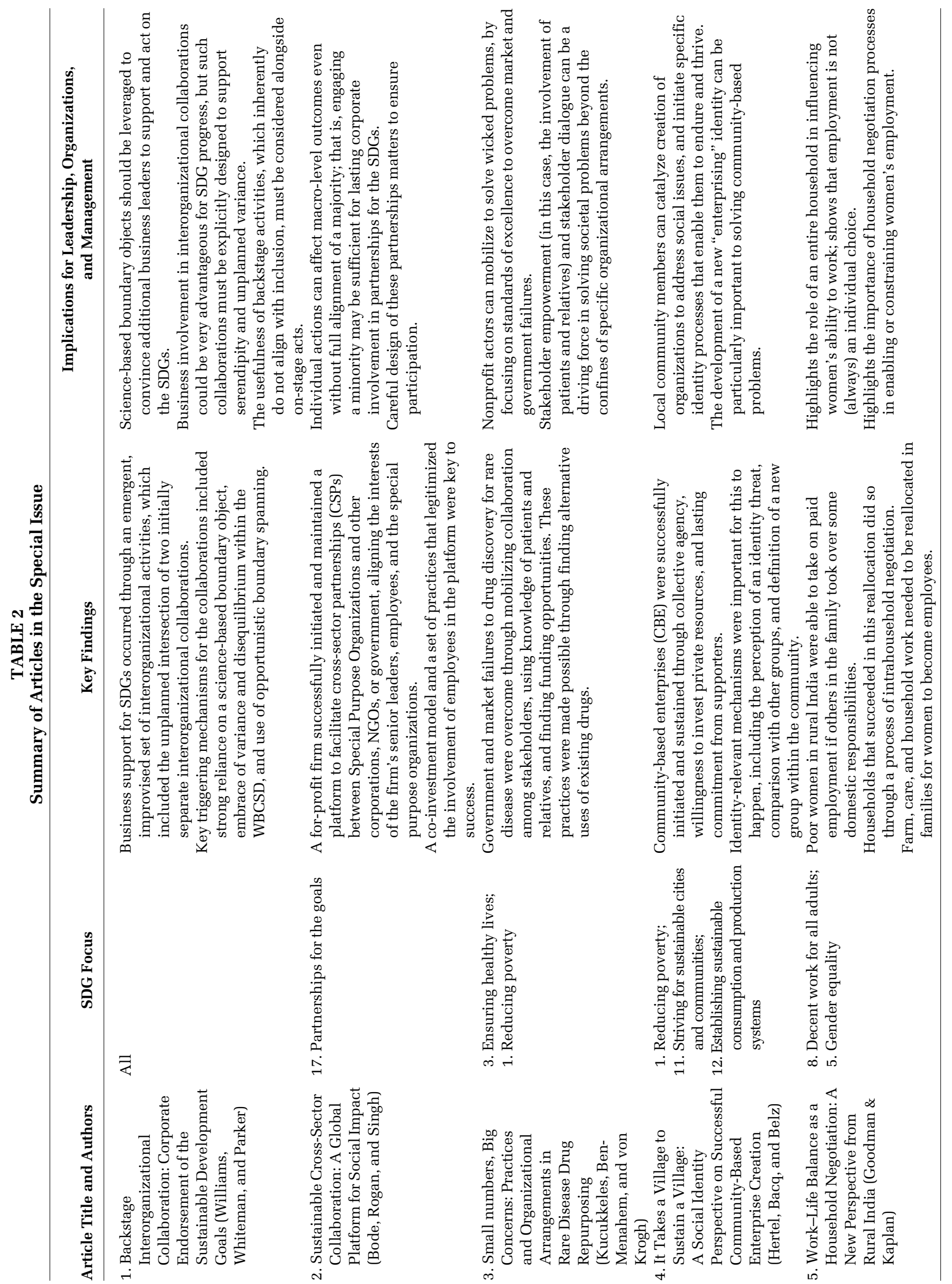




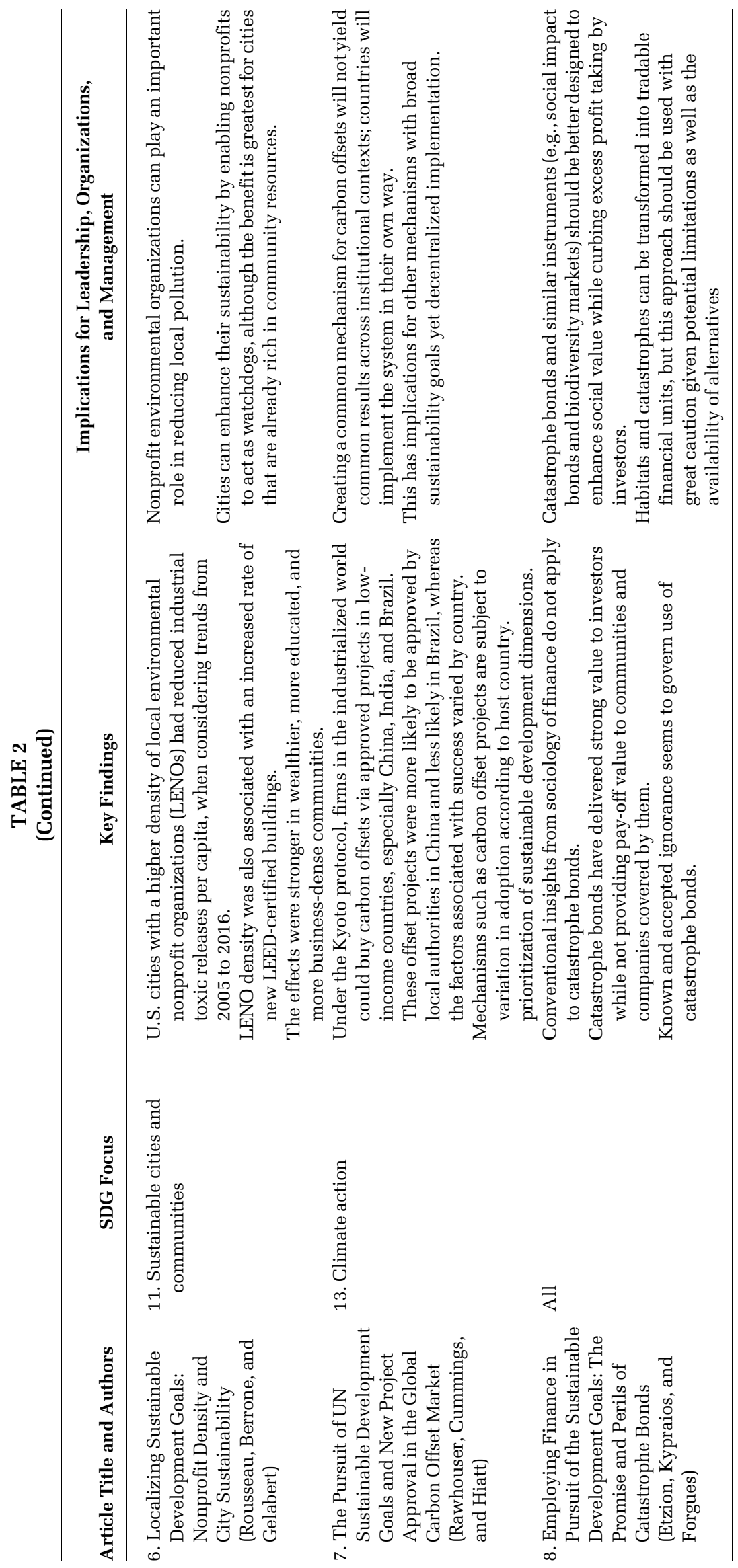


The authors use the anthropological lens of household decision-making to uncover four distinct negotiation styles that were engaged to reallocate work within families and enable women to maintain paid work outside the household. Accordingly, Goodman and Kaplan show how attaining SDGs 8 (decent work for all) and 5 (gender equality) demands taking into account how individual actions and choices are shaped by their family and community circumstances, as well as other social structures.

\section{Theme 2: Conceptualizing Complexity}

Whereas the articles mentioned so far engage complexity by considering interactions across levels of analysis, other ways in which management scholars engage complexity are further illustrated by the articles in this special issue. Our conceptual approaches allow us to consider the construction, contestation and perpetuation of meanings, actions, and arrangements, and we embrace the influence of collective and individual identities, power and interests, and day-to-day practices on these processes. Several articles highlight how particular interests produce certain outcomes and demonstrate that pursuit of the SDGs must account for how these interests are distributed and negotiated. Rawhouser, Cummings, and Hiatt ("The Pursuit of UN Sustainable Development Goals and New Project Approval in the Global Carbon Offset Market”) show how approvals for the UN's Clean Development Mechanism (CDM) carbon offset projects differ by the aspects of sustainability (social, economic, and environmental) they address and further by idiosyncratic differences in host country policymaker preferences, which may reflect the location of decision-making within different types of government departments. In other words, international mechanisms to enable sustainable development are influenced by their local interpretation, suggesting both a multilevel explanation and one that accounts for distinct organizational arrangements and policymaker interests. An additional article that shows how interests shape outcomes and condition the attainment of social value is that by Etzion, Kypraios, and Forgues ("Employing Finance in Pursuit of the Sustainable Development Goals: The Promise and Perils of Catastrophe Bonds"). This article offers a cautionary tale on the value derived from catastrophe bonds, designed to insure against extreme weather events such as hurricanes, flooding, or forest fires. The authors find that catastrophe bonds have delivered strong value to investors but have failed to provide pay-off value to the communities and companies covered by them. Clearly, as interest in financial mechanisms to address aspects of sustainability—such as climate risk, biodiversity loss, or maintenance of natural capital—rises, we need to take heed of the message that our underlying models are inherently incomplete, which, coupled with lack of transparency and accessibility of the mechanisms themselves, diminishes the social value that can be attained.

Finally, complexity and divergent interests and identities are found to be productive in making progress on the SDGs in other cases. The article by Williams, Whiteman, and Parker ("Backstage Interorganizational Collaboration: Corporate Endorsement of the Sustainable Development Goals") traces the involvement of business in formulating and supporting the SDGs. Providing critical context and history, this article also shows how emergent and unplanned dynamics between two initially separate interorganizational collaborations, one led by the World Business Council for Sustainable Development (WBCSD) and one led by the UN, resulted in WBCSD member companies endorsing the SDGs. Key to this process was the use of a science-based boundary object, openness to serendipity, and unplanned variance. Backstage (a.k.a. offstage) activities also played a role, although such activities inherently do not align with inclusion. Related to but different from these emphases, Kucukkeles, Ben-Menahem, and von Krogh ("Small Numbers, Big Concerns: Practices and Organizational Arrangements in Rare Disease Drug Repurposing") show that purposeful actions can lead to convergence of interests in cases where existing organizational arrangements and market failures have prevented progress on societal challenges. In their article on the repurposing of drugs for treating rare disease, they show how field actors were able to create new organizational arrangements to reinforce a standard of excellence (using state-of-the-art knowledge and resources) and apply it to the cure of rare diseases. These authors discover that certain practices-the mobilization of a collaborative community, knowledge creation by researchers and patients, and catalyzing alternative funding models-helped overcome the market failures and unlocked innovation and solutions.

In sum, by looking across levels of analysis and conceptualizing the complexity of arrangements that may misdirect or enable progress on the SDGs, the articles in this volume offer excellent "proof of concept" that management scholarship can be productively trained toward issues of societal importance and offer evidence that informs how businesses and other organizations may better tackle such issues.

\section{Theme 3: Goldilocks-Size Real-World Problems}

A final theme, which can be seen in all of the articles, highlights an orientation toward practical 
real-world problems needed to make progress on the SDGs. Each article has a slightly different scope, in terms of SDG goals and geographic focus, but each also provides a strong match between the nature of the data collected and analyzed and the conclusions reached. Whereas some articles comment on financial and policy arrangements at a market level (Etzion et al.; Rawhouser et al.), and others on organizational arrangements at a city level (Rousseau et al.), several take on organizational and individual negotiations and practices within a targeted field of activity (Bode et al., Kucukkeles et al.; Williams et al.). Finally, others consider community- and household-scale actions (Goodman \& Kapla; Hertel et al.). In all cases, authors have chosen to focus on specific phenomena from which we can draw more transferable insights; for example, to other markets, fields, organizations, and communities. Hence, they seem to pass the test of creating useful social science through an explicit focus on addressing real problems and getting as close to the action of those problems as possible (Sarewitz, 2016).

\section{OPPORTUNITIES FOR FURTHER DEVELOPMENT OF MANAGEMENT SCHOLARSHIP ON THE SDGs}

Although the articles in this volume reveal many ways in which management scholarship can further progress on various SDGs, we must reflect on the perils of such scholarship and the opportunities to further its utility. As mentioned, a key criterion for relevant, problem-oriented research is accountability to those most affected by the problems (Sarewitz, 2016). With the SDGs having such a diverse and global focus, this implies a wide swath of potential engagement with those affected. We note that the published articles in this volume represent only a limited geographical reach, suggesting there is much more work needed to understand how management scholarship can serve those who face the problems defined by the SDGs. With the exception of Goodman and Kaplan's ethnography in rural India, the articles largely capture convenings and market activities centered in the United States and Europe. To be sure, the engagement of diverse businesses and other organizations in working toward progress on the SDGs (as illuminated in Williams et al. and Bode et al.) implies a more global reach. But, if we were to evaluate what the articles in this volume could say about real-world problems related to the SDGs through "boots on the ground," our footprints would be largely found in the industrialized global north. This is not a critique of the particular articles nor their value, so much as an observation-made many times before (e.g., Barkema, Chen, George, Luo, \& Tsui, 2015;
Henrich, Heine, \& Norenzayan, 2010)—that management scholarship has a Western bias, perhaps in part due to data access and in part due to the history of the field. Studying SDG goals and how organizations, management, and leadership are working toward them ought to throw open many opportunities to break out of this bind. We hope the variety of articles and focal points in this volume will be taken as a launching point to inspire further work, drawing similarly on rich data and rigorous analysis from farther afield.

A second opportunity to further the utility of management scholarship on the SDGs comes from encouraging more work done at the microlevel of analysis. Somewhat surprisingly, only one (Goodman and Kaplan) of the eight articles in this special issue focuses mostly on the individual (and family) level of analysis, in exploring women's employment in India. It is possible that the profile of studies in the special issue is a proper reflection of the SDGs, as the SDGs can be interpreted as primarily focused on economy-wide and organizational-level efforts to advance health, education, environment, and prosperity for all. Even individual well-being is often examined at the aggregate level. We believe, however, that knowledge is needed specifically to understand how people suffer or thrive, as individuals, when attention is put on organizational and policy arrangements to deliver the SDGs. We also urge scholars conducting individual-level research to take into account the context within which outcomes are observed and be open to discoveries that challenge accepted understanding. For example, we cannot assume that well-being, stress, justice, and income considerations in developed economies, where most current studies on these topics have been conducted, are similar in developing or base-of-the-pyramid economies. With issues as urgent and important as those captured in the SDGs, it is imperative that we find ways to encourage much more management scholarship that can inform-and critique-the way business and other organizations might make progress and improve their impact on economic and social outcomes for employees and individuals across diverse settings.

In taking up all of the opportunities and challenges of high-quality research on the SDGs, scholars are encouraged to leverage our full toolkit of methodological approaches. We are excited that the articles in this volume represent a useful mix of quantitative (Rawhouser et al., Rousseau et al.; Etzion et al.) and qualitative approaches (Goodman et al., Hertel et al., Kucukkeles et al., and Williams et al.), as well as mixed methods (Bode et al.). Specific methods employed range from ethnographic fieldwork to quantitative exploratory analysis and modeling, demonstrating that insights into real-world problems need not be 
limited to a certain kind of data or analytical approach. Indeed, with such a range of approaches, SDG foci, and levels of analysis, we do risk building new windows and staircases within a Winchester Mystery House if we do not keep an eye on the purpose of the research. How can this methodological flexibility be used to build, reinforce, or challenge the evidence base so that our scholarship can say more-and more robustly-about chosen Goldilocks problems? To be sure, many journals seek only novelty in empirical and theoretical contributions, lessening the tendency for scholars to build on what has gone before. But many journals are also embracing the importance of scholarship that is problem-focused (e.g., George, Howard-Grenville, Tihyani, \& Joshi, 2016), which helps in managing the tension between novelty for the sake of novelty and scholarship that takes seriously the solving of puzzles and problems related to the social good. $A M D$ in particular welcomes problem-focused studies that explore new territory but with concrete empirical foundations and respect for what has come before. To put this another way, $A M D$ welcomes robust studies that engage in empirical exploration (Bamberger, 2018) to truly understand the pressing problems of the world, as the studies in this special issue aspire to do.

A final note on the nature of the SDGs themselves is warranted. Given that there are 17 of them, and each envisions bold transformation from the current state, we might rightly question how realistic this bold agenda is. In the words of UN officials, "We are setting out a supremely ambitious and transformational vision." Can the goals actually be attained? Can individual businesses, governments, and scientific organizations do their parts to attain the seemingly impossible? History suggests that success might be attainable, but it also suggests that skirting failure is far from guaranteed (Sitkin, Miller, \& See, 2019). The Apollo 11 moon landing, the dramatic reduction of infectious diseases in many parts of the world, the building of Egyptian pyramids, and the construction of the Great Wall of China and Angkor Wat in Cambodia highlight what humankind can accomplish. On the other hand, great ambitions often disappoint. In the United States, a relatively wealthy nation, President Lyndon Johnson's War on Poverty failed to eliminate or even appreciably reduce poverty. Efforts to build an accepting multicultural society have not succeeded in South Africa. Efforts to stem the tide of oceanic pollution have largely failed. Efforts to create peace on the planet have failed miserably.

Existing research focused on organizational characteristics that enable audacious goal attainment offers some hints as to what is possible with the SDGs. Based on this work, organizations with a reasonable degree of internal slack coupled with swagger borne of recent success, possibly in non-SDG pursuits, seem to be best positioned to undertake the exceedingly difficult work (Sitkin et al., 2019; Sitkin, See, Miller, Lawless, \& Carton, 2011). Complacency, however, can derail such organizations (see Lant, Milliken, \& Batra, 1992; Levitt \& March, 1988). Organizations without slack and recent success probably should consider contributing only through small wins; see Weick (1984) (Sitkin et al., 2011; Sitkin, Miller, \& See, 2017). In considering how businesses and other organizations can tackle the SDGs, it might be worthwhile to consider the size and scope of problems that are tackled. It is important to recall that the 17 goals contain within them a number of more specific targets-169 in all-that may well be more effective and productive starting points for some or even many organizations.

Overall, there is a great deal of complexity involved in the pursuit of the SDGs. As such, management researchers cannot just continue "business as usual." We have a professional duty, as social scientists, to contribute knowledge that is robust and useful for solving the world's toughest social problems. Natural scientists are doing their part. We believe that social scientists in business schools must contribute. This special issue offers eight studies that are inspirational examples for other scholars to follow. We have 10 more years to achieve the SDGs, or at least to make substantial progress toward their achievement. Management scholars have a dire obligation to contribute to this ambitious but necessary agenda to ensure a sustainable future for all.

Jennifer Howard-Grenville University of Cambridge

Gerald F. Davis University of Michigan

Thomas Dyllick University of St. Gallen

C. Chet Miller University of Houston

Stefan Thau INSEAD

Anne S. Tsui University of Notre Dame Peking University Fudan University

\section{REFERENCES}

Ansari, S., Wijen, F., \& Gray, B. 2013. Constructing a climate change logic: An institutional perspective 
on the "tragedy of the commons". Organization Science, 24(4): 1014-1040.

Bamberger, P. A. 2018. Clarifying what we are about and where we are going. Academy of Management Discoveries, 4(1): 1-10.

Bansal, P. 2003. From issues to actions: The importance of individual concerns and organizational values in responding to natural environmental issues. Organization Science, 14(5): 510-527.

Bansal, P. 2019. Sustainable development in an age of disruption. Academy of Management Discoveries, 5(1): 8-12.

Bansal, P., \& Hoffman, A. J. 2012. The Oxford handbook of business and the natural environment. New York: Oxford University Press.

Barkema, H. G., Chen, X. P., George, G., Luo, Y., \& Tsui, A. S. 2015. West meets East: New concepts and theories. Academy of Management Journal, 58(2): 460479.

Colquitt, J. A., Conlon, D. E., Wesson, M. J., Porter, C. O., \& Ng, K. Y. 2001. Justice at the millennium: A metaanalytic review of 25 years of organizational justice research. Journal of Applied Psychology, 86(3): 425445 .

Community for Responsible Research in Business and Management (cRRBM). 2017. A vision of responsible research in business and management: Striving for useful and credible knowledge. Available at www. rrbm.network. Accessed November 12, 2019.

Crane, A., McWilliams, A., Matten, D., Moon, J., \& Siegel, D. S. 2008. The Oxford handbook of corporate social responsibility. New York: Oxford University Press.

Davis, G. F. 2015. What is organizational research for? Administrative Science Quarterly, 60: 179-188.

Dyllick, T. \& Muff, K. 2016. Clarifying the meaning of sustainable business: Introducing a typology from business-as-usual to true sustainability. Organization \& Environment, 29(2): 156-174.

Ferraro, F., Etzion, D., \& Gehman, J. 2015. Tackling grand challenges pragmatically: Robust action revisited. Organization Studies, 36(3): 363-390.

Gaines, J., \& Jermier, J. M. 1983. Emotional exhaustion in a high stress organization. Academy of Management Journal, 26(4): 567-586.

George, G., Howard-Grenville, J., Joshi, A., \& Tihanyi, L. 2016. Understanding and tackling societal grand challenges through management research. Academy of Management Journal, 59(6): 1880-1895.

SDG compass: The guide for business action on the SDGs. 2015. New York: GRI, UNGC, \& WBCSD. Available at https://sdgcompass.org/wp-content/uploads/2016/05/
019104_SDG_Compass_Guide_2015_v29.pdf. Accessed December 8, 2019.

Henrich, J., Heine, S. \& Norenzayan, A. 2010. Most people are not WEIRD. Nature, 466: 29.

Howard-Grenville, J., Nelson, A., Earle, A., Haack, J., \& Young, D. 2017. 'If chemists don't do it, who's going to?' peer-driven occupational change and the emergence of green chemistry. Administrative Science Quarterly, 62(3): 524-560.

Judge, T. A., Piccolo, R. F., Podsakoff, N. P., Shaw, J. C., \& Rich, B. L. 2010. The relationship between pay and job satisfaction: A meta-analysis of the literature. Journal of Vocational Behavior, 77(2): 157-167.

Kim, Y. H., Davis, G. F. 2016. Challenges for global supply chain sustainability: Evidence from conflict minerals reports. Academy of Management Journal, 59(6): 18961916.

Lant, T. K., Milliken, F. J., \& Batra, B. 1992. The role of managerial learning and interpretation in strategic persistence and reorientation: An empirical exploration. Strategic Management Journal, 13: 585-608.

Leana, C. R., \& Meuris, J. 2015. Living to work and working to live: Income as a driver of organizational behavior. Academy of Management Annals, 9(1): 55-95.

Levitt, B., \& March, J. G. 1988. Organizational learning. Annual Review of Sociology, 14: 319-340.

Luo, X., Zhang, J., Marquis, C. 2016. Mobilization in the internet age: Internet activism and corporate response. Academy of Management Journal, 59: 2045-2068.

Mair, J., Wolf, M., Seelos, C. 2016. Scaffolding: A process of transforming patterns of inequality in small-scale societies. Academy of Management Journal, 59: 2021-2044.

Majchrzak, A., Griffith, T. L., Reetz, D. K., \& Alexy, O. 2018. Catalyst organizations as a new organization design for innovation: The case of hyperloop transportation technologies. Academy of Management Discoveries, 4: 472-496.

Marr, J. C., \& Thau, S. 2014. Falling from great (and not-sogreat) heights: How initial status position influences performance after status loss. Academy of Management Journal, 57(1): 223-248.

Montiel, I., \& Delgado-Ceballos, J. 2014. Defining and measuring corporate sustainability: Are we there yet? Organization \& Environment, 27(2): 113-139.

Nakamura, M., Pendlebury, D., Schnell, J., \& Szomszor, M. 2019. Navigating the structure of research on sustainable development goals. Policy, 11: 12.

Pettit, N. C., Yong, K., \& Spataro, S. E. 2010. Holding your place: Reactions to the prospect of status gains and losses. Journal of Experimental Social Psychology, 46(2): 396-401. 
PwC 2015. Make it your business: Engaging with the Sustainable development goals. Available at https://www.pwc.com/gx/en/sustainability/SDG/SDG \%20Research_FINAL.pdf. Accessed July 16, 2019.

Rittel, H. W., \& Webber, M. M. 1973. Dilemmas in a general theory of planning. Policy sciences, 4(2): 155-169.

Sarewitz, D. 2016. Saving science. The New Atlantis, vol. 49(Spring/Summer): 4-40.

Schaltegger, S., \& Wagner, M. 2006. Integrative management of sustainability performance, measurement and reporting. International Journal of Accounting, Auditing and Performance Evaluation, 3(1): 1-19.

Schüssler, E., Rüling, C. C., \& Wittneben, B. B. 2014. On melting summits: The limitations of field-configuring events as catalysts of change in transnational climate policy. Academy of Management Journal, 57(1): 140171.

Sitkin, S. B., Miller, C. C., \& See, K. E. 2017. The stretch goal paradox: Ambitious targets are widely misunderstoodand widely misused. Harvard Business Review, 95(1)(January-February): 92-99.

Sitkin, S. B., Miller, C. C., \& See K. E. 2019. Risks of addressing vs. ignoring our biggest societal problems: When and how moon shots make sense. In R. P. Gephart, C. C. Miller, \& K. Helgesson Svedberg (Eds.), The Routledge companion to risk, crisis, and emergency management. New York: Routledge.
Sitkin, S. B., See, K. E., Miller, C. C., Lawless, M. W., \& Carton, A. M. 2011. The paradox of stretch goals: Organizations in pursuit of the seemingly impossible. Academy of Management Review, 36(3): 544-566.

Sonenshein, S., DeCelles, K. A., \& Dutton, J. E. 2014. It's not easy being green: The role of self-evaluations in explaining support of environmental issues. Academy of Management Journal, 57(1): 7-37.

United Nations. 2015. Transforming our World: the 2030 Agenda for Sustainable Development. Resolution adopted by the General Assembly on 25 September 2015. Available at https://sustainabledevelopment.un. org/post2015/transformingourworld. Accessed July 16, 2019.

Watts, D. J. 2017. Should social science be more solutionoriented? Nature Human Behaviour, 1(1): 0015.

Weick, K. E. 1984. Small wins: Redefining the scale of social problems. American Psychologist, 39: 40-49.

Whiteman, G., \& Cooper, W. H. 2011. Ecological sensemaking. Academy of Management Journal, 54(5): 889-911.

Whiteman, G., Walker, B., \& Perego, P. 2013. Planetary boundaries: Ecological foundations for corporate sustainability. Journal of Management Studies, 50(2): 307-336.

Xie, J. L., \& Johns, G. 1995. Job scope and stress: Can job scope be too high? Academy of Management Journal, 38(5): 1288-1309. 
Copyright of Academy of Management Discoveries is the property of Academy of Management and its content may not be copied or emailed to multiple sites or posted to a listserv without the copyright holder's express written permission. However, users may print, download, or email articles for individual use. 